\title{
Observations from the EV Project in Q3 2013
}

December 2013

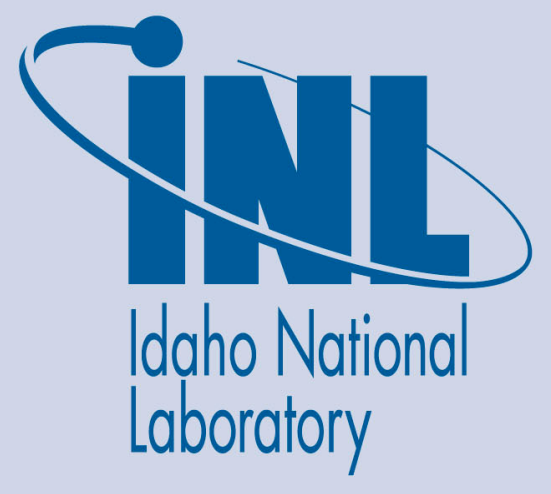

The INL is a U.S. Department of Energy National Laboratory operated by Battelle Energy Alliance 
INL/EXT-13-30965

\title{
Observations from the EV Project in Q3 2013
}

December 2013

\author{
Idaho National Laboratory \\ Idaho Falls, Idaho 83415
}

http://www.inl.gov

Prepared for the

U.S. Department of Energy

Assistant Secretary for Energy Efficiency and Renewable Energy

Under DOE Idaho Operations Office

Contract DE-AC07-05ID14517 


\section{"IV Project}

\section{Observations from The EV Project in Q3 2013}

\section{Fast Facts}

By the end of the $3^{\text {rd }}$ quarter (Q3), 2013:

- 109 million miles were recorded on EV Project vehicles

- Over 3.5 million charging events were recorded

- Over 29,000 megawatt-hours of energy were delivered by EV Project charging units

- Over 8,200 Nissan Leafs, Chevrolet Volts and Smart ForTwo Electric Drive vehicles have provided data

- 8,250 residential electric vehicle supply equipment units (EVSE) have reported data

- 3,985 commercial (publicly available, workplace and fleet) EVSE were installed

- 107 DC fast chargers (DCFC) were installed

In Q3 2013:

- DCFC usage frequency dropped $40 \%$ from the previous quarter to 2.3 charging events per DCFC per day. It should be noted that a use fee for DCFC was initiated during Q3

- DCFCs in the Washington state region had the most frequent usage of any of the regions, with an average of 5.2 events per DCFC per day

- Public level 2 charging unit usage frequency increased $19 \%$ from the previous quarter but was still low at 0.26 events per EVSE per day (or 1.8 events per EVSE per week)

- The San Francisco region saw the most frequent public level 2 EVSE usage, averaging 0.55 events per EVSE per day (or 3.9 events per EVSE week)

- Charging event duration at public level 2 EVSE varied widely from region to region, with an average low of 2.2 hours per event in Tucson to 9.1 hours per charge in Philadelphia

- Residential EVSE across the country were used less frequently but for longer durations - usage frequency dropped $6 \%$ to 0.8 events per EVSE per day and average duration of charging events increased $4 \%$ to 11.9 hours per charging event

- Leaf drivers charged $78 \%$ of the time at home and $22 \%$ away from home (a $1 \%$ reduction in home charging from the previous quarter )

- Volt drivers charged $85 \%$ of the time at home and $15 \%$ away from home, consistent with the previous quarter

- Leafs continued to average 1.1 charging events per day driven

- Volts continued to average 1.5 charging events per day driven

\section{Observations}

\section{Number of participants}

The number of vehicles and residential EVSE in the project stayed nearly constant in Q3 2013, with no new participants added. A small number of participants left the project during the quarter. The number of publicly accessible level 2 EVSE and DCFC increased slightly during the quarter. 


\section{"IV Project}

\section{Public EVSE usage}

DCFC usage nationally decreased 40\% in Q3 from the previous quarter, most likely because the Blink network began charging fees for DCFC use in all project regions during the quarter. DCFCs in the Washington state region were used most frequently, averaging 5.2 charging events per fast charger per day in the quarter. Washington state, Oregon, San Francisco, and San Diego regional DCFC usage frequency averages were all higher than the national average of 2.3 times per day. In Q3, regional average DCFC event durations ranged from 17 and 21 minutes per charging event and resulted in between 6 and $9 \mathrm{kWh}$ of energy transferred per event, on average regionally. In comparison, public level 2 EVSE charging events averaged 6 to $12.5 \mathrm{kWh}$ in 2 to 9 hours.

Public level 2 EVSE usage frequency increased $17 \%$ over the previous quarter, offsetting some of the decrease in DCFC usage. However, DCFCs remained vastly more popular than the slower public level 2 EVSE. The national average for the number of charging events per public level 2 EVSE per day in Q3 was only 0.26 (or 1.8 charging events per EVSE per week). The San Francisco region saw the most frequent public level 2 EVSE usage of 0.55 events per EVSE per day (or 3.9 events per EVSE week), on average. The Atlanta (0.48), San Diego (0.48), and Los Angeles (0.41) regions were also above the national average for public level 2 charging frequency.

EV Project participants averaged 4.3 hours connected to public EVSE per charging event this quarter, down 6\% from the previous quarter. Duration of plug-in events at public EVSE varied widely from region to region, from 2.2 hours per charge in Tucson to 9.1 hours per charge in Philadelphia. Time spent drawing power per plug-in event was much more consistent, ranging from 3.0 hours per event in Philadelphia to 1.7 hours per event in Chattanooga. Overall, utilization of public level 2 EVSE remained low. The percentage of time EVSE were connected to vehicles in Q3 ranged from 9\% in San Diego and San Francisco to less than 1\% in Tucson, Chattanooga, and Houston. Usage of public level 2 charging sites is specific to the location and nature of each site, the mix of vehicle makes/models being charged, and other factors. This topic will be explored in a future report.

\section{Residential EVSE usage}

Nationwide, residential EVSE were used slightly less frequently - 0.8 charging events per EVSE per day, down $6 \%$ from the previous quarter - and for slightly longer durations in Q3. The national average residential EVSE charging event duration was 11.9 hours per event, up 4\% from the previous quarter. Residential EVSE were connected to vehicles from about $35 \%$ to $50 \%$ of the day, on average across regions. Vehicles were drawing power from EVSE at home for $6 \%$ to $10 \%$ of the day.

The San Francisco and Los Angeles regions were among the top four regions with the highest usage of public EVSE and fast chargers in Q3. These two regions also had the lowest residential EVSE usage frequency in Q3, at 0.6 and 0.8 charging events per EVSE per day, 


\section{"IV Project}

respectively. Additionally, these two regions averaged the highest residential EVSE time connected per charging event - around 12.5 hours - and the highest residential EVSE energy per charging event - over $8 \mathrm{kWh}$. In summary, participants in these regions tended to perform fewer, longer charging events at home and more frequent, shorter charging events in public, compared to the rest of the country.

\section{Demand on the Electric Grid}

On any given weekday in Q3, from $35 \%$ to $45 \%$ of residential EVSE were connected to vehicles between midnight and 6:00 AM. Residential EVSE were typically unplugged from their vehicles on weekday mornings between 6:00 AM to 10:00 AM and plugged back in between 4:00 PM and 10:00 PM. In regions where electric utilities do not offer widely adopted time-of-use rates for EVs, charging demand on the electric grid from residential EVSE was low during the day and increased gradually in the evening, peaking sometime between 6:00 PM and 10:00 PM. In some of these regions, there was also a small spike in demand at night at a certain point, indicating that some participants were motivated to delay charging until a specific time, such as the start of off peak electricity rates. In San Diego and San Francisco, where a large number of project participants have elected EV time-of-use rates, charging demand remained low until spiking sharply at midnight and 1:00 AM.

For publicly available level $2 \mathrm{EVSE}$, in most regions, the Q3 median demand begins to rise between 6:00 AM and 8:00 AM, peaks between 9:00 AM and noon, and slowly falls off until midnight. In regions where public level 2 EVSE is not used much, demand falls to near zero between noon and 6:00 PM. In some regions, demand has a second peak in the early afternoon.

Charging demand from DCFCs rises after 6:00 AM to a peak around 6:00 PM and falls off to zero by midnight. Aggregate peak demand in Q3 for the DCFCs was $0.4 \mathrm{MW}$, which was half the peak demand of the 2,663 public level 2 EVSE used in Q3.

For the full Q3 2013 EV Project charging infrastructure usage report, visit http://avt.inl.gov/pdf/EVProj/EVProjInfrastructureQ32013.pdf.

\section{Vehicle Charging Location Preference}

Data received from participating Nissan Leafs and Chevrolet Volts was analyzed to determine the percentage of charging events performed at home and away from home. Excluding the $6 \%$ of charging events performed at an unknown location, Leaf drivers performed $78 \%$ of their charging events at home and $22 \%$ away from home in Q3. Leaf charging location preference has remained steady in 2013 - the split was 79\% home / 21\% away in Q2 2013 and 78\% / 22\% in Q1 2013. Regionally in Q3, Leaf drivers in Memphis had the strongest preference for home charging of any region, with $87 \%$ home / 13\% away. Consistent with the previous quarter, San Francisco, Los Angeles, and Knoxville saw the highest away-from-home charging preference in Q3, with $72 \%$ home / $28 \%$ away, $71 \%$ home / 29\% away, and $70 \%$ home / $30 \%$ away, respectively. 


\section{"IV Project}

The national average for Volt drivers in Q3 was 85\% home /15\% away. This percentage stayed constant throughout the first three quarters of 2013. Volt drivers in Memphis, Chattanooga, and Houston averaged the highest regional at-home charging percentage in Q3, with $93 \%$ home I $7 \%$ away in Memphis, $90 \%$ home / 10\% away in Chattanooga, and $87 \%$ home $/ 13 \%$ in Houston. Oregon and Los Angeles showed the strongest preference for highest away-fromhome with $82 \%$ home / $18 \%$ away.

\section{Vehicle Charging Frequency}

In each quarter since the beginning of the project, including in Q3, Leafs drivers have averaged 1.1 charging events per day when the vehicle was driven. This average has varied regionally between 1.0 and 1.2 charging events per day.

Volt drivers in Q3 charged 1.5 times per day driven, on average nationally. Since the beginning of the project, this average has stayed between 1.4 and 1.5 charging events per day driven. In Q3, regional charging frequency ranged from 1.3 events per day in San Diego to 1.6 events per day in Chicago and Dallas/Ft. Worth.

\section{Driving Distance}

Leaf drivers averaged 28.4 miles per vehicle day nationally in Q3 (considering only days when the vehicle was driven). This was a decrease of about 1 mile from the previous quarter's average. Regional average daily driving distance ranged from $25.9 \mathrm{mi}$ per vehicle day in LA to 31.6 mi per day in Dallas/Ft. Worth.

Volts averaged 41.1 miles per day driven nationally in Q3, consistent with the previous quarter. Regionally, Volt average distance per day in Q3 ranged from $38.2 \mathrm{mi}$ per vehicle day in LA to $58.6 \mathrm{mi}$ per day in Chattanooga. (Note that there is a small number of Volts in Chattanooga so atypical behavior by just one or two drivers could skew the average.)

Volts averaged $45 \%$ more miles per day than the Leaf national average. This trend of Volts driving considerably farther per day than Leafs was consistent across all regions. Although Volt drivers averaged nearly 13 miles more miles each day than Leaf drivers, the average distance driven between charge events per vehicle for Leaf and Volt drivers was much closer, due to higher Volt charging frequency. Leafs averaged 26.2 miles between charges and Volts averaged 28.1 miles between consecutive charging events.

Because the Volt is an extended range electric vehicle, drivers have the option of driving in either electric-only (EV) mode or extended range mode once the EV mode range has been exhausted. In Q3, Volts averaged 73\% of their miles in EV mode, down from $75 \%$ in the previous quarter. Regional EV mode driving varied from $54 \%$ in Chattanooga to $76 \%$ in Oregon. 


\section{"IV Project}

For the full Q3 2013 EV Project Leaf and Volt reports, visit

http://avt.inl.gov/pdf/EVProj/EVProjectNissanLeafQ32013.pdf and

http://avt.inl.gov/pdf/EVProj/EVProjectChevroletVoltQ32013.pdf

For the full Q3 2013 EV Project reports and past reports visit http://avt.inl.gov/evproject.shtml

For an explanation of these reports, visit

http://avt.inl.gov/pdf/EVProj/EVProjectTestingReportsDiscussion.pdf

\section{About The EV Project}

The EV Project is the largest electric vehicle infrastructure demonstration project in the world; initiated, designed and managed by ECOtality North America (ECOtality), with a budget of over $\$ 230$ million United States Dollars (USD), equally funded by the United States (U.S.) Department of Energy (DOE) through the American Recovery and Reinvestment Act (ARRA) and ECOtality and its partners. The EV Project will deploy and study over 12,000 alternating current (AC) Level 2 electric vehicle supply equipment (EVSE) charging stations for residential and commercial use, as well as up to 200 dual-port direct current (DC) Fast Chargers (DCFCs) in conjunction with the usage data from approximately 8,300 Nissan LEAF ${ }^{\mathrm{TM}}$, Chevrolet Volts and Smart ForTwo Electric Drive vehicles. This project will collect and analyze data, and publish lessons learned on vehicle and EVSE use, and driver behavior. This material is based upon work supported by the DOE under Award Number DE-EE-0002194.

The current schedule for the conclusion of EV Project data collection by the Idaho National Laboratory (INL) is December 31, 2013. During early 2014, the individual 2013 Fourth Quarter and summary reports will be generated and published. Through the remainder of 2014, additional summary, technical, and lessons learned reports will be generated and published by the INL. 